\title{
An evaluation of the public sector optometric service provided within the health districts in KwaZulu-Natal, South Africa
}

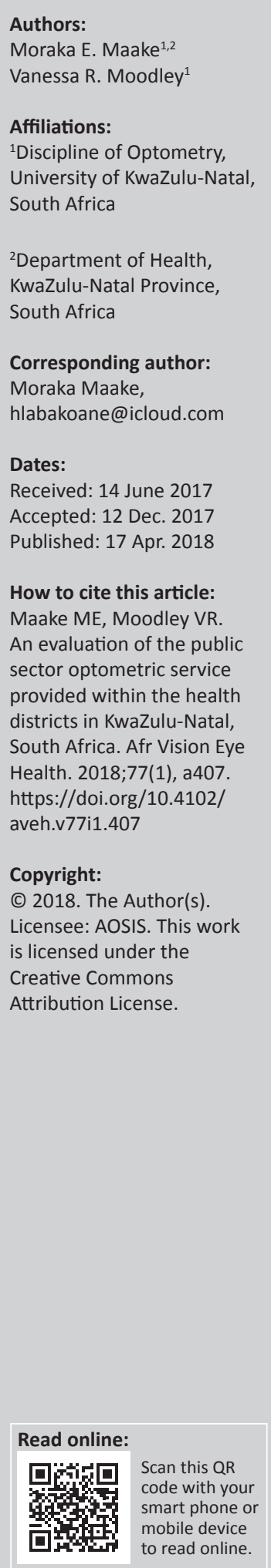

Background: In South Africa, optometry has been traditionally positioned within the private sector. The situation has gradually changed over the past two decades, with optometry being introduced into the public sector in many parts of the country. Despite the growing numbers, optometrists are still new within the public health sector, motivating this study to evaluate the eye care services they provide.

Methods: A cross-sectional, retrospective, descriptive study was undertaken. Stratified random selection was applied to select the study sites, and systematic sampling was used to select patients' files. A saturated sample of public sector optometrists employed in the selected districts completed study questionnaires. Data were analysed using the Statistical Package for Social Sciences, Version 21.

Results: A total of 2968 records were reviewed, and gender distribution was $67.6 \%$ female and $32.4 \%$ male. Refraction $(86.73 \%)$ was the most frequently conducted test, followed by ophthalmoscopy $(74.73 \%)$, colour vision $(0.07 \%)$ and gonioscopy $(0.03 \%)$. The response rate for the questionnaires was $64.7 \%$. Optometric outreach services were conducted by $54.5 \%$ of optometrists, and the majority (83.3\%) reported that the farthest outreach facility was more than $50 \mathrm{~km}$ from their base hospital. The availability of equipment at outreach facilities was less as compared to base hospitals, while some reported not having the necessary equipment even at base hospitals. None of the optometrists did contact lens fitting at outreach facilities. A lack of equipment was cited as one of the reasons for not providing this service by $100 \%$ of optometrists. Most optometrists (63.6\%) believed that more than $30 \%$ of their referrals might have been avoided if they had prescribed therapeutic agents to manage ocular conditions.

Conclusion: Introducing optometrists within the public sector improves access to services for rural communities. However, the minimum standard of optometric care is not practised, allegedly because of a lack of equipment. Therefore, resources should be made available to enable optometrists to provide comprehensive optometric services. In addition, the study highlighted the need for more optometry posts in rural communities and for the implementation of career growth paths to attract and retain optometrists within the public sector.

\section{Introduction}

The number of people suffering from visual impairment (VI) and blindness globally continues to rise, even though the World Health Organization (WHO) estimates that approximately $80 \%$ of VI can be prevented or cured. ${ }^{1}$ The WHO further estimates that 253 million people are visually impaired worldwide, of whom 217 million are classified to have low vision (moderate and severe VI) and 36 million are classified as blind. The leading causes of low vision are uncorrected refractive errors (URE) (53\%) and unoperated cataracts (25\%). Unoperated cataracts (35\%) and URE (21\%) are also the leading causes of blindness. Although there has been a decrease in the prevalence of VI over the last 20 years, the WHO estimates that the number of people with VI could triple because of population growth and ageing. ${ }^{1}$ It was previously estimated that 32.7 million of the world's visually impaired are in Africa. ${ }^{2}$ A 2011 study $^{3}$ conducted in rural South Africa identified cataracts and URE as the most common causes of VI and blindness among diabetic black South Africans aged 40 years and older. Naidoo et al. ${ }^{4}$ also identified refractive errors and cataracts as the leading causes of VI in a South African health district. Visual impairment may negatively impact the quality of life of the affected individuals as well as the economic productivity in developing countries such as South Africa. Most adults with severe VI

Note: Additional supporting information may be found in the online version of this article as Online Appendix 1: https://doi.org/10.4102/ aveh.v77i1.407-1 and Online Appendix 2: https://doi.org/10.4102/aveh.v77i1.407-2 
and blindness may be denied opportunities to actively participate in the mainstream economy, thus creating an added burden on their government to cater for their needs. Similarly, visually impaired children may be excluded from the education system as most developing countries do not have adequate facilities to cater for them. As a consequence of such exclusions, these children are likely to be dependent on social grants and handouts during their adult lives.

In the rural KwaZulu-Natal (KZN) province, cataracts were identified as one of the leading causes of blindness ${ }^{4}$ and have also been identified as one of the national health priorities. ${ }^{5}$ However, it appears that the country has difficulty in dealing with the burden of cataracts - a survey ${ }^{6}$ indicated that the cataract surgical ratio (CSR) in South Africa was 1226 cataract operations per million population per year, which was lower than both the originally targeted 2000 and the subsequent lowered value of 1500. An inappropriate use of surgeons' time on performing other non-surgical work is cited as one of the causes for not achieving the targeted CSR.

A survey by Statistics South Africa estimated the population of South Africa to be 55653646 and found that approximately $9.2 \%$ of the total population used eye glasses as a form of corrective device. ${ }^{7}$ The survey further indicated that $10.3 \%$ of the population have a seeing or sight disability, the highest of all forms of disabilities surveyed. The National Department of Health previously estimated the prevalence of blindness in the country to be $0.75 \%,{ }^{8}$ while Naidoo et al. ${ }^{4}$ recently estimated a prevalence of $0.9 \%$, with leading causes being cataracts, refractive errors and glaucoma.

Statistics by the Health Professions Council of South Africa (HPCSA) reveal that there are 3697 registered optometrists. ${ }^{9}$ On average, South Africa currently has an optometrist to patient ratio of 1:15 052. Comparatively, Australia, with 5313 registered optometrists ${ }^{10}$ and a population of $24127200,{ }^{11}$ has a ratio of 1:4541, which is one of the highest per capita ratios of optometrists in the world. The United States of America, meanwhile has an average ratio of approximately 1:7848. ${ }^{12}$ The WHO recommends a minimum ratio of 1:100 000 for optometrists or refractionists and 1:250 000 for ophthalmologists. ${ }^{13}$ However, it remains questionable as to whether the application of these recommended ratios will be adequate to achieve the Vision 2020 targets. In developing nations like South Africa, however, because of the unequal distribution of optometrists between urban and rural areas, the ratios have to be calculated separately to obtain sensible data. ${ }^{14}$

Walls ${ }^{15}$ indicated that optometry has much to offer towards eye care services in government hospitals. Historically, in South Africa optometry has been a profession traditionally positioned within the private sector, with optometrists practicing primarily in solo, group or association practices. The situation has slowly changed over the past two decades, with optometry gradually being introduced into the public health sector in many parts of the country. The accessibility to optometrists by patients utilising public health facilities is still poor when one considers that only 262 optometrists (Nxumalo F, personal communication, March 24, 2017) are employed by public health facilities to cater for the needs of $70.7 \%$ of the population utilising public services. ${ }^{16}$ This translates to a ratio of 1:150 179. In contrast, private optometrists serve the $28 \%$ of the population that utilise private facilities, ${ }^{15}$ resulting in a ratio of 1:4537. Despite the numbers of public sector optometrists increasing annually in certain provinces, provinces such as the Western Cape and Northern Cape still lag behind.

Although the number of public sector optometrists is still considered too low to meaningfully meet eye care needs, they are more than twice the 113 ophthalmologists (Nxumalo F, personal communication, March 24, 2017) employed within the public sector. This small number of ophthalmologists working within the public sector makes it virtually impossible for them to adequately deal with the high surgical demands as well as the non-surgical treatment and management of ocular diseases. The numerical advantage and further training in ocular diagnostic and therapeutic areas of optometrists make their inclusion in the restructured primary eye care system in South Africa crucial for the National Health Insurance (NHI) to succeed. ${ }^{17}$ Incorporating the new optometry scope into the eye care service delivery protocol would alleviate the workload burden on ophthalmologists.

Despite the increase in the number of optometrists and ophthalmologists employed in the public sector, it is still virtually inadequate to significantly reduce the prevalence of VI and blindness. In addition, of concern are the anecdotal reports indicating that even in facilities where optometrists are employed, they are not practising to their full scope. The number of optometry posts needed or the scope of practise requirements was not empirically determined prior to optometrists being introduced into the public sector. The post-apartheid eye care leadership presumably recognised that the public sector eye care services across the country were inadequate, with a common cause being the absence of public sector optometry posts. Hence, in an attempt to rectify this situation and address the issue of preventing avoidable blindness, provinces began creating public sector optometry posts without coherent strategies in place. The KZN province has created optometry posts for many years, but the impact that these employed optometrists are making on the eye care services within the public sector in KZN has not been evaluated. Hence, this study aimed to evaluate the services rendered by the optometrists towards informing the planning and development of future public sector optometric services.

\section{Methodology}

A cross-sectional, retrospective, descriptive study was undertaken. Stratified random selection was used to select the study sites (five hospitals) from the four selected 
health districts, namely eThekwini, iLembe, Ugu and uMgungundlovu. The study population comprised patients who presented at optometry clinics in the five selected hospitals from January to December 2012, and public sector optometrists based at the four selected health districts in 2012.

Data collection tools comprised the following:

- A chart to capture data from the clinical record cards of patients examined at the selected hospitals from January to December 2012. Information captured on the chart included the patient's biographical data: chief complaint, test results, diagnosis and management. No names or personal identity information was recorded to maintain patient confidentiality (Online Appendix 1).

- Semi-structured questionnaires administered to optometrists. Questions on biographical information, their clinical roles and experiences as well as perceptions about the new expanded scope of optometry were included (Online Appendix 2).

Systematic sampling was used to select available patients' files from the selected hospitals. Clinical records of patients were reviewed and captured, and every captured record was coded to ensure anonymity.

The questionnaires were distributed to all public sector optometrists employed at the public health facilities in the chosen districts, and informed consent was obtained from all participating optometrists prior to the commencement of the research. All the participants were assured that confidentiality would be maintained and they were also made aware that their participation was voluntary.

Data with individual reference were captured on Microsoft Excel and transferred to the Statistical Package for Social Sciences (SPSS), Version 21, for further analysis.

\section{Ethical considerations}

Written permission to conduct this study was granted by all the relevant authorities from the Department of Health (KZN province), and ethical clearance to perform this study was obtained from the Humanities and Social Sciences Research Ethics Committee (HSSEC), University of KwaZulu-Natal, South Africa.

\section{Results}

\section{Patients}

\section{Demographics}

A total of 2968 files from the five selected hospitals were reviewed, of which the majority were female $(67.6 \%)$ and $32.4 \%$ were male. The age range of the patients varied from 1 to 97 years, with a mean of 47.8 years and a standard deviation of 21.1 years. Of the patients, $14 \%$ were less than 18 years old and $70.5 \%$ were aged 40 years and older.

\section{Reasons for consultation}

Although some patients indicated more than one reason for consultation, reduced vision $(82.0 \%)$ was mentioned as the most frequent reason, followed by complaints (20.2\%) not stipulated on the data collection tool, referrals from other facilities $(14.6 \%)$, routine eye examinations $(6.7 \%)$, ocular pain $(3.2 \%)$, ocular trauma $(1.7 \%)$ and binocular vision-related complaints (1.4\%).

\section{Tests conducted}

The frequency of tests conducted is shown in Figure 1.

\section{Diagnosis and management strategies employed}

Refractive error (74.2\%) was the most frequently diagnosed condition, followed by pathology (29.5\%). The management strategies employed are shown in Figure 2.

A comprehensive distribution of all patients presenting with different chief complaints, their diagnosis and management is shown in Table 1.

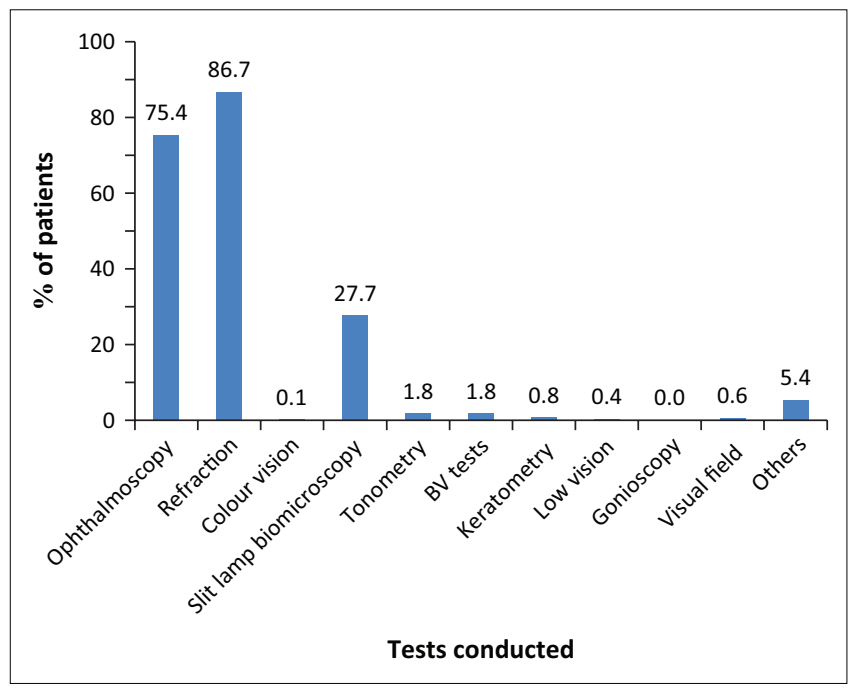

BV, binocular vision.

FIGURE 1: The frequency of tests conducted on patients by optometrists.

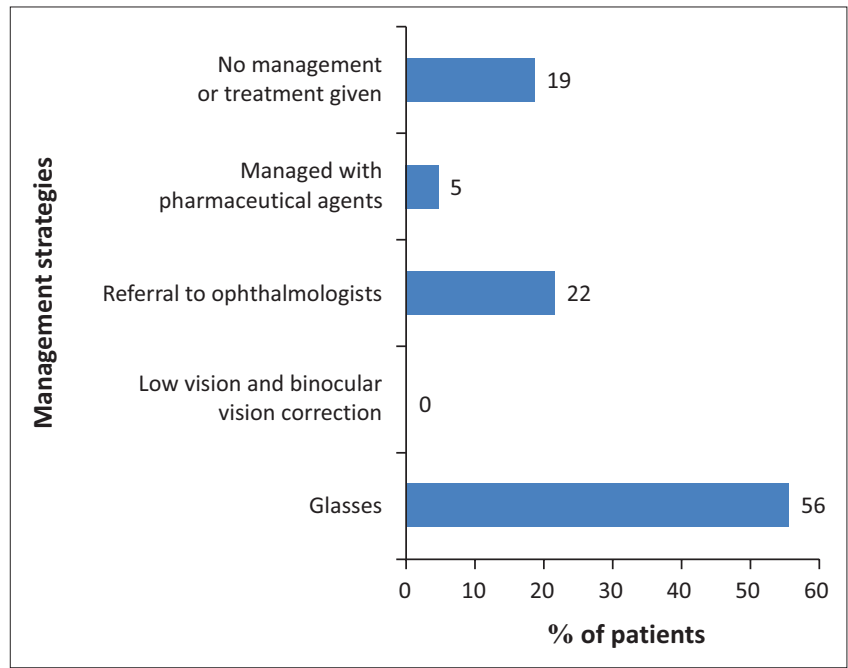

FIGURE 2: Management strategies (\%) implemented for patients. 
TABLE 1: Showing diagnosis and management of each of the presenting chief complaints.

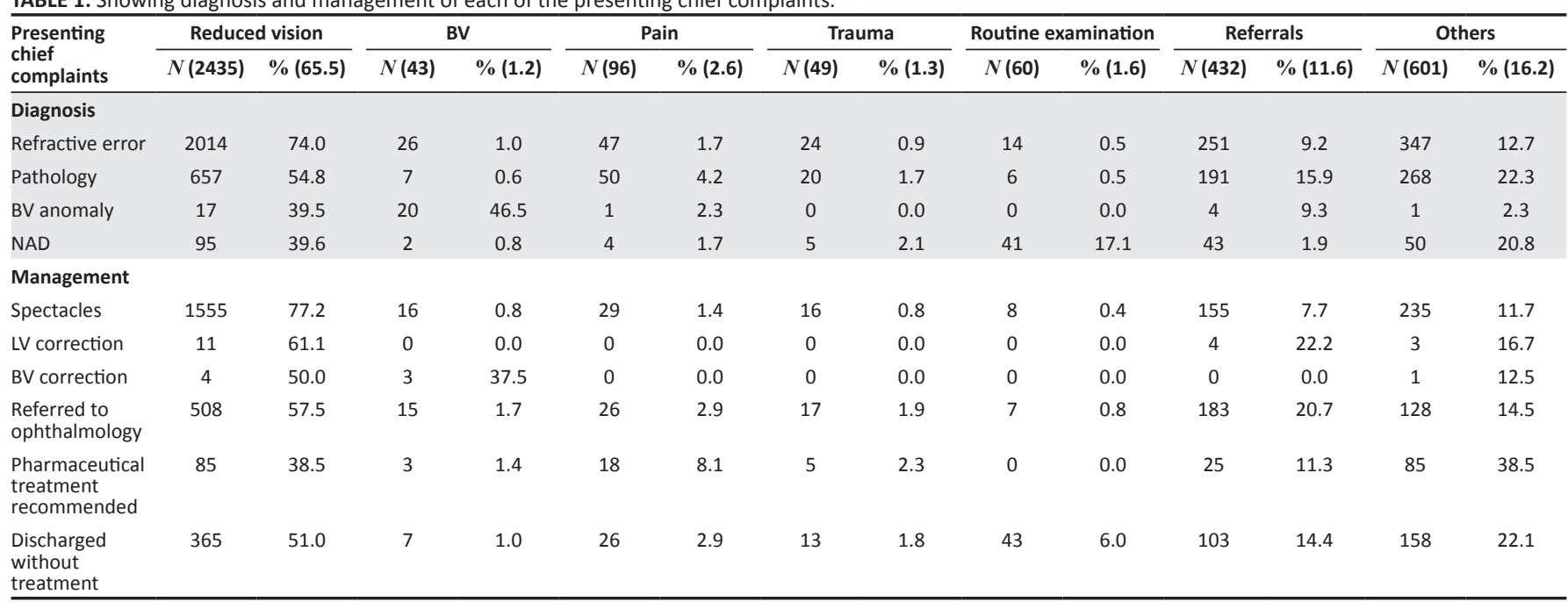

BV, binocular vision; LV, low vision; NAD, no abnormality detected.

\section{Optometrists}

\section{Profile}

The response rate for the optometrists' questionnaires was $64.7 \%$. The majority $(90.9 \%)$ of optometrists were younger than 30 years, with $81.8 \%$ being female and the rest (18.2\%) male. The majority $(54.5 \%)$ of the optometrists had less than 5 years post-qualification or registration (PQR) working experience, 9.1\% had more than 20 years of PQR working experience, and the rest (36.4\%) had PQR experience of between 5 and 10 years. Only 18.2\% were based in rural areas, while $81.8 \%$ were based in urban and peri-urban areas. All the optometrists were employed at entry level optometry posts, with none of the study participants employed at the level of chief optometrist or higher. The duties were classified as either production (54.5\%), which involves only doing clinical duties; or both production and supervisory (45.5\%), where the optometrist does both clinical and managerial duties.

\section{Outreach}

Outreach services were conducted by the majority (54.5\%) of optometrists. However, all the optometrists rendering outreach services were based in rural and semi-urban areas, with none of the urban-based optometrists rendering outreach services. The outreach services are conducted on a rotational basis, as different facilities are visited on different days of the week. The number of outreach facilities visited by each optometrist ranged from 3 to 10.

Distance to outreach facilities: A third (33.3\%) of the optometrists who conducted outreach services reported that their nearest outreach facility was less than $10 \mathrm{~km}$ from their base hospital, while another third reported that the nearest facility was more than $50 \mathrm{~km}$ from their base hospital. Only $16.7 \%$ of the optometrists reported that the farthest outreach facility was less than $20 \mathrm{~km}$ away from their base hospital, while the rest $(83.3 \%)$ indicated that the farthest outreach facility was more than $50 \mathrm{~km}$ away from their base hospital.
Number of patients seen per month at outreach facilities: A third $(33.3 \%)$ of the optometrists reported that they examined less than 50 patients per month at their outreach facility, $50 \%$ reported that they examined between 50 and 200 patients and $16.7 \%$ reported that more than 200 patients were examined monthly.

Waiting period at outreach facilities: Half (50\%) of the optometrists reported that the waiting period at their outreach facility was less than one month, while the other half reported that the waiting period at the outreach facility was between one and three months. The majority (66.7\%) of the optometrists reported that subsequent to seeing patients, the referral waiting period from the outreach facility to their base hospital was less than one month, while the remainder had a waiting period of between one and six months.

Services provided at outreach facilities: The majority (83.3\%) of the optometrists conducting outreach services reported that they did vision screening, refraction and the dispensing of spectacles at outreach facilities. Only $16.7 \%$ provided low vision assessments at outreach facilities. None of the optometrists reported doing any ocular diagnostic procedures, binocular vision and contact lenses at outreach facilities.

Reasons for not providing services: The reasons mentioned by the optometrists for optometric services not being provided at outreach facilities are shown in Figure 3.

\section{Base hospitals}

Number of patients seen at base hospitals: Two thirds $(66.7 \%)$ of the optometrists reported that they examined more than 200 patients at their base hospital, and one-third $(33.3 \%)$ reported that fewer than 50 patients were examined monthly at their base hospital.

Services provided: The majority (90.9\%) of the optometrists reported performing refraction and low vision assessments, $81.8 \%$ reported also ordering and dispensing spectacles, $72.7 \%$ reported performing vision screening and ocular diagnostic 


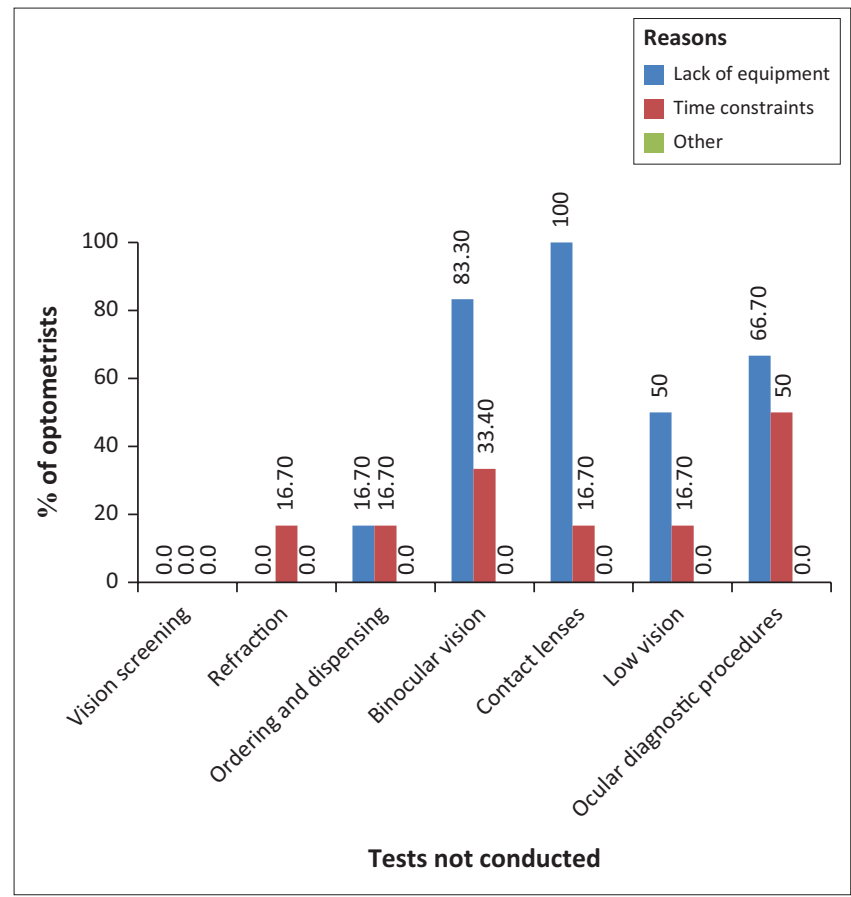

FIGURE 3: Reasons given by optometrists for services not provided at their outreach facility.

procedures, and 54.5\% and 9.1\% reported providing services relating to binocular vision and contact lenses, respectively.

Reasons for not providing services: The reasons mentioned by the optometrists for services not being provided at their base hospital are shown in Figure 4.

Referrals of patients by optometrists: The majority (90.9\%) of the optometrists referred their patients to ophthalmologists at a frequency of more than once a week, whereas $27.3 \%$ and $18.2 \%$ referred to other health professionals and general practitioners, respectively, at the same frequency. In addition, $18.2 \%$ referred to private optometrists at a frequency of only once a week.

The conditions for which patients were most frequently referred more than once a week were as follows: $81.8 \%$ of the optometrists referred patients for crystalline lens conditions, 54.5\% referred patients for glaucoma and 36.4\% referred patients for retinal conditions and binocular vision or paediatric conditions.

Equipment: The availability of equipment is shown in Figure 5.

\section{Optometry scope expansion to include ocular therapeutics}

When asked about their opinion and knowledge of the recent optometry scope expansion to include ocular therapeutics, all the optometrists (100\%) agreed that optometrists should be able to prescribe ocular therapeutic drugs for the treatment of anterior segment ocular diseases (ASOD), and 90.9\% stated that optometrists were adequately trained to diagnose ASOD. Participating optometrists reported often recommending the appropriate medication to the consulting medical doctor when referring. In addition, all the optometrists indicated that they would wish to use drugs to treat ocular diseases

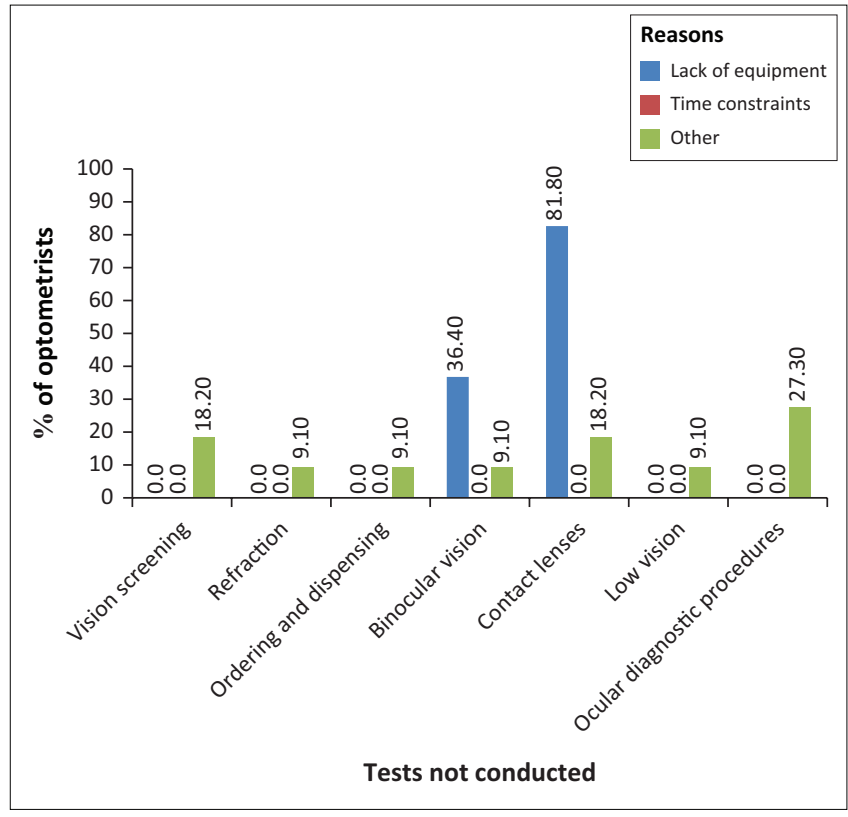

FIGURE 4: Reasons given by optometrists for services not provided at their base hospital.

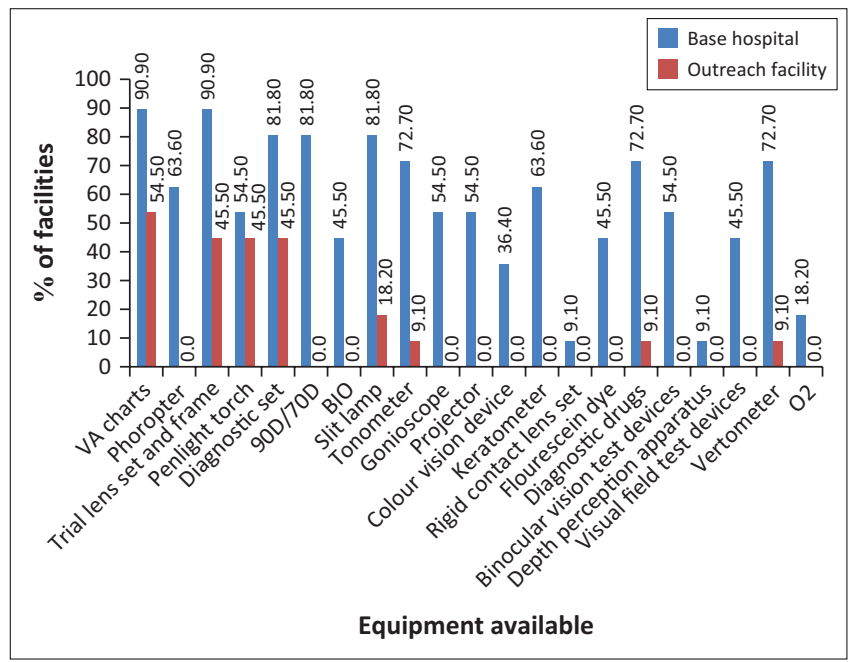

VA, vsual auity chart; 90D/70D, 90 Diopter or 70 Diopter double aspheric fundus examination lens; BIO, binocular idirect ohthalmoscope; 02 , any other optometry equipment or instrument not initially listed Online Appendix 2.

FIGURE 5: Availability of equipment at base hospitals and outreach facilities.

and that they would be interested in undertaking further training to allow them to prescribe such drugs.

\section{Expected effect of ocular therapeutic agents prescription on referral rate}

Approximately two thirds (63.6\%) of the optometrists believed that more than $30 \%$ of their referrals might be avoided if they were allowed to prescribe therapeutic agents. The benefits of the scope expansion cited by optometrists are summarised as follows:

- reduced number of patient consultations or workload for ophthalmologists

- reduced costs to government, for example, transportation costs of referred patients

- improved access to eye health care services for patients

- early management of ocular conditions. 


\section{Discussion}

\section{Patients}

\section{Demographics of patients}

Although the South African population is reported to have a median age of $20-29$ years, ${ }^{18}$ this study revealed that the uptake of eye health services is low among this population group. This may have resulted from youth prioritising job seeking since unemployment is high among this population group, ${ }^{19}$ so seeking health care may not be their priority. There was also a low uptake of eye health services by those younger than 18 years. It is possible that this group may have already been attended to at school by the government school health services. However, as the visual demands in both education and the working environment are high, eye health care promotions that target children and young adults need to be performed to encourage the uptake of eye health services. Presbyopia as well as the visual impact of other systemic diseases affecting the eyes may have influenced a high percentage $(70.5 \%)$ of older age groups (40 years and above) as global surveys indicate that the prevalence of diseases such as diabetes mellitus and hypertension increases with age..$^{20,21}$

The majority (67.6\%) of patients identified in the study were female, as corroborated by the Statistics South Africa (2011) finding that, across all race groups, women are more likely than men to have visited a health worker. ${ }^{22}$ The same survey further revealed that a larger proportion of men than women rated their health as either 'good' or 'very good'. Presumably, males also rate their eye health as being good and do not see the need to visit an eye health facility. Eye health education can be included in campaigns or promotions targeting males, which can serve to encourage the utilisation of all health services available. Previous studies revealed that men have high mortality rates as compared to women. ${ }^{23}$

\section{Presenting complaints}

Almost two-thirds of all presenting complaints was reduced vision, with a small proportion of subjects presenting to optometrists with ocular pain and ocular trauma. This could be because of the 'triage' or sorting system employed at public sector facilities, whereby nurses, as the first contact health care workers, screen and direct patients to the relevant eye care personnel or professionals. Patients reporting reduced vision or are suspected of having URE are more likely to be referred to an optometrist. Conversely, patients complaining of pain and trauma in the eyes are more likely to be directed to an ophthalmologist. In hospitals where optometrists work independently (without ophthalmologists or ophthalmic nurses), they would presumably be exposed to a variety of complaints as a result of having almost all eye conditions referred to them. In these instances, the optometrists have to manage most of the conditions falling within their scope of practice and refer others to ophthalmologists or other relevant health practitioners.

\section{Tests}

Optometrists frequently performed ophthalmoscopy and refractions, while other tests such as tonometry, colour vision, visual field, keratometry or binocular vision were conducted less frequently. However, the eliminated tests are part of the minimum tests required for a basic vision and eye health consultation, as defined by the HPCSA. ${ }^{24}$ The cited lack of equipment and time constraints must be addressed by health care facilities to ensure that public sector patients receive the minimum expected standard of clinical care. This will also contribute to practitioner job satisfaction. The lack of equipment and infrastructure was mentioned in a previous study by public sector optometrists as one of the priorities that needed intervention for retention purposes. ${ }^{25}$

\section{Diagnosis}

A high number of patients seen by optometrists presented with complaints of reduced vision and were refracted and diagnosed with refractive errors. Notably, almost one-third $(32.6 \%)$ of subjects who presented with complaints of reduced vision were also diagnosed with pathological conditions, suggesting that some pathological conditions presented with refractive errors which patients may have presumed were the only problem at the time of going to an eye health facility. This further emphasises the important role of optometrists in the identification and management of other pathological conditions of the eye. While attending to refractive conditions, they may diagnose sight or life-threatening conditions that require appropriate referrals, for example, glaucoma and tumours such as retinoblastoma. With the increasing prevalence of diabetes ${ }^{20}$ and hypertension ${ }^{21}$ in countries like South Africa, these systemic conditions may lead to ocular conditions such as retinopathy and secondary glaucoma; optometrists need to ensure that tonometry, visual fields and dilated fundus examinations are conducted on all patients as part of the normal optometric standard of care. The lack of contact lens services at public sector facilities means that keratoconic patients may not be adequately managed, potentially resulting in academic exclusion for scholars and the loss of income or work opportunities in adults. It is therefore important for health authorities to consider including contact lens care as well as other important eye health care services such as binocular vision.

\section{Optometrists}

\section{Demographics of optometrists}

It is encouraging to note that many young optometrists are selecting to work within the public sector $-90.1 \%$ of the participants were younger than 30 years of age. This is good for the public sector as these optometrists still have many working years to contribute before retirement, and hence, an investment in their development for the long-term benefit of the country should be considered. Of note, however, is that experienced practitioners do not work in semi-urban or rural areas. Ideally, there should be a mix of experience in all areas of practice. 
More than three-quarters of optometrists were female, despite a 2006 student study ${ }^{26}$ suggesting that males were more than twice as likely to prefer work in a hospital as females when asked about the kind of practice they would join upon completion. The study also revealed that females were more risk averse than males since they showed less likelihood of opening their own practices. Hence, a possible reason why there is a higher representation of females than males in the study is because females may consider public sector hospital employment as a less risky option. It is also possible that the high representation of females could be related to a higher enrolment of females at optometry training institutions. ${ }^{27}$

\section{Area of practice}

Few of the optometrists were based in rural areas, with the majority located in urban and semi-urban areas. This means that most of them are catering for communities that are more likely to already have access to private optometric services, even though it is acknowledged that some may be financially excluded from accessing urban-based private practices. However, the levels of poverty are far higher in rural areas, making more people dependent upon public sector facilities for eye health care. With the population in KZN being almost equal in rural and urban areas, it is recommended that the numbers of optometrists serving them should, at the least, be evenly distributed to increase access in these underserved areas. The impact of poor access was highlighted in a previous study which suggested that the lack of access to refractive services may have been one of the reasons for the low uptake of spectacles in semi-rural and rural populations. ${ }^{4}$ Therefore, increasing access to optometrists will improve the use of eye services. This was found in a study conducted to evaluate the impact of eye health care services delivered in rural communities of the Mankweng area in Limpopo, where there was a high utilisation (85.9\%) of optometric services by patients seeking eye health care services. ${ }^{28}$ The availability of affordable optometry services from the University of Limpopo Optometry Clinic may have contributed to an improved access to eye health care services for these communities since they are located adjacent to the university. Accordingly, there is a need for stakeholders to come together to provide rural communities with affordable services in their vicinity, which may lead to improved access and utilisation of eye care services.

None of the optometrists interviewed were employed at the level of chief optometrist or higher, possibly highlighting a lack of career growth opportunities for optometrists in the public sector. A concern is that this phenomenon may eventually lead to a loss of skills to the private sector to the detriment of eye health care services for the majority of the population dependent on the public sector. Ramson et al. ${ }^{25}$ ranked career growth as the second highest required intervention stated by public sector optometrists when asked about their potential retention within the public service. Therefore, there is a need for career growth opportunities and improved working and living conditions for optometrists if retention and recruitment strategies are to succeed. ${ }^{27}$

\section{Outreach}

The majority (54.5\%) of optometrists reported that they conduct outreach services on a rotational basis to health facilities that do not have optometric services. Initiatives such as these improve access to optometry services for communities residing in the outlying areas of their districts. This study, however, highlighted that not all basic optometric services were provided during community outreach programs. The main reasons for not providing all optometric services seem to be a lack of equipment at these facilities and time constraints. Although the care at base hospitals is also not optimal, patients attending these outreach facilities are being deprived of the standard of care that patients at base hospitals receive, raising serious ethical concerns. There is a need to adequately equip these facilities to enable optometrists to conduct comprehensive eye examinations. Comprehensive needs assessments must be undertaken to consider whether outreach facilities should have full-time optometrists, as this study revealed that some facilities have a waiting period of more than a month. Time constraints was not mentioned as a reason for not providing comprehensive services at base hospitals, yet was mentioned several times as a reason for not providing some of the services at outreach facilities. This may suggest that the time spent travelling to outreach facilities may hamper the provision of comprehensive services to patients, further supporting the need to assess whether fulltime or more frequent eye health care services at outreach facilities is indicated. This will address population coverage, one of the three dimensions identified by the WHO for progressing towards universal health coverage for member states, as South Africa proceeds with the introduction of the NHI. One of the goals for the NHI under population coverage is to extend health care coverage to all South Africans, ensuring that populations that are in the greatest need and those experiencing the greatest difficulty in obtaining health care are prioritised. ${ }^{17}$ Therefore, communities in remote and rural areas should be prioritised by having eye health care services closer to where they live.

\section{Referrals}

It has also been noted that crystalline lens conditions were the most frequently referred condition, exacerbating the cataract backlog. Glaucoma was the second most frequently referred condition. In other parts of the world, optometrists diagnose and manage glaucoma patients ${ }^{29}$ which, if implemented in South Africa, may significantly enhance patient care as many of these optometrists visit areas that currently do not have any access to an ophthalmologist. Without access to eye health care services for glaucoma patients, the number of patients affected by preventable blindness will continue to rise. The recent scope expansion for optometrists to prescribe therapeutic drugs and to manage glaucoma presents an opportunity for South Africa to utilise optometrists to manage or co-manage such conditions and release ophthalmologists to focus on the cataract backlogs and other surgical and advanced ophthalmic conditions. 
Other anterior segment and retinal conditions were the third most frequently referred condition. Utilising optometrists in the management or co-management of some of the anterior segment conditions may result in a reduction of long delays currently experienced by patients who are referred to ophthalmologists. Treating or managing patients closer to where they live will also reduce costs to the state for transporting patients, as well as reducing the loss of work hours for employed patients. This study thus promotes a collaboration between optometrists and ophthalmologists in the KZN province and in making strides in providing these historically underserved populations with eye health care services that are of a high quality, as well as being accessible and cost-effective.

Almost a quarter of the subjects in a previous study cited finance as the reason for not seeking eye health care services, despite the study being conducted in communities that lived within a $10 \mathrm{~km}$ radius of eye health care facilities. ${ }^{28}$ Finance for transport may therefore not be the only factor for those patients in this study who live more than $50 \mathrm{~km}$ away from optometric facilities. The financial difficulty may include the costs of the optical device. Provincial eye health care models should include financial structures that make the provision of optical appliances affordable to patients. Cost-effective access to optometric services must also be accompanied by eye health promotion initiatives within communities. These initiatives must educate the public on the importance of having eye health examinations and advice on where to locate eye health facilities that are close to communities.

\section{Services}

Patients diagnosed with common, minor anterior segment conditions such as blepharitis or conjunctivitis were managed by medical doctors or referred for treatment. However, optometrists are very capable of managing these minor pathological conditions without having to refer to the already overburdened medical doctors at the respective facilities. This is corroborated by records which revealed that $5 \%$ of all cases were managed by optometrists in the form of appropriate ocular pharmaceutical treatment recommended to the medical doctor. Some optometrists felt that more than $30 \%$ of their referrals could be reduced if they were permitted to use drugs to treat some ocular diseases; consequently, this may reduce the workload of ophthalmologists and ophthalmic medical officers. Optometrists also indicated their willingness to undertake further training in order to improve their existing scope and supported continuous learning to keep themselves abreast of changes in their profession.

\section{Conclusion}

This study highlights the improved access to eye health care services achieved through the inclusion of optometrists into the human resource structure within the public sector. Many historically underserved rural communities have, for the first time, access to eye health care services. However, the concern is that the regulated minimum standard of optometric care is not being provided, primarily because of a lack of equipment and cited time constraints. In addition, the optometrists who are appropriately trained are underutilised when one compares the full professional scope with current practices at the facilities examined in this study. Public sector patients seeking care at these facilities are therefore deprived of the comprehensive eye health care services that optometrists are expected to provide. There is a moral and ethical obligation to ensure that these patients, who generally cannot afford to visit private optometrists, receive the minimum standard of eye health care services as defined by the regulatory authority. Therefore, there is a need for relevant stakeholders to develop strategies to improve the quality of eye health care services in this sector.

This study recommends that government allocates appropriate resources to optimise the services that optometrists can provide within the public sector. It is evident that if public sector optometrists were given more training and resources, they could significantly contribute to reducing the referral rate of patients, thus reducing the costs of service delivery to government and bringing services closer to where patients reside.

Appropriate strategies, advocacy and political will are needed to create more optometry posts in rural communities, with the implementation of career growth paths and support systems to attract and retain optometrists. The various stakeholders in eye health care, such as government, institutions of higher learning, regulatory bodies, professional associations, and industry and non-governmental organisations, should collaborate to ensure that eye health care services improve in accessibility, quality and cost-effectiveness.

\section{Acknowledgements Competing interests}

The authors declare that they have no financial or personal relationships that may have inappropriately influenced them in writing this article.

\section{Authors' contributions}

M.E.M. was responsible for the study design, data collection, analysis and writing of the article. V.R.M. supervised the project and also contributed to the writing of the article.

\section{References}

1. WHO. Visual impairment and blindness; Fact Sheet No 282 [www.who.int]. [cited/ accessed 2017 Nov 22]. Available from: http://www.who.int/mediacentre/ factsheets/fs282/en/

2. WHO. Global data on visual impairments 2010 [www.who.int]. WHO/NMH/ PBD/12.01. [cited/accessed 2017 Mar 09]. Available from: http://www.who.int/ blindness/GLOBALDATAFINALforweb.pdf

3. Mabaso RG, Oduntan AO. The prevalence and causes of visual impairment and blindness among adults with diabetes mellitus aged 40 years and older receiving treatment at government health facilities in the Mopani District, South Africa. S Afr Optom. 2014;73(1):8-15. https://doi.org/10.4102/aveh.v73i1.2

4. Naidoo KS, Sweeny D, Jaggernath J, Holden B. A population-based study of visual impairment in the Lower Tugela health district in KZN, SA. S Afr Optom. 2013;72(3):110-118. https://doi.org/10.4102/aveh.v72i3.284 
5. Cook CD, Knight SE, Croften-Briggs I. Prevalence and causes of low vision in KwaZulu-Natal. S Afr Med J. 1993;83:590-593.

6. Cook C, Leucona K. South Africa's cataract surgery rates - why are we not meeting our targets? SAMJ. 2011;101(8):510-512.

7. Statistics South Africa. Community survey 2016 statistical release P0301 [www. statssa.gov.za]. [cited/accessed 2017 Mar 09]. Available from: www.statssa.gov.za

8. Department of Health, Directorate of Chronic Disease, Disability and Geriatrics. National guidelines: Prevention of blindness in South Africa, Pretoria [www. westerncape.gov.za]. [cited/accessed 2017 Apr 27]. Available from: http://www. westerncape.gov.za/text/2003/blindness.pdf

9. HPCSA. Statistics [www.hpcsa.co.za]. [cited/accessed 2017 Mar 09]. Available from: http://www.hpcsa.co.za/Publications/Statistics

10. Optometry Board of Australia. Optometry Board of Australia Registrant Data. Reporting period: 1 October 2016-31 December 2016 [homepage on the Reporting period: 1 October $2016-31$ December 2016 Thomepage on the
Internet]. [cited/accessed 2017 Mar 10]. Available from: http://www. optometryboard.gov.au/About/Statistics.aspx

11. Australian Bureau of Statistics. Australian Demographics Statistics 3101.0 [www. abs.gov.au]. [cited/accessed 2017 Mar 28].

12. American Optometry Association. AOA Excel, Jobson Medical Information LLC. An action-oriented analysis of the state of the optometric profession [www.reviewob. com]. 2013 [cited/accessed 2017 Mar 20]. Available from: http://www.reviewob. com/Data/Sites/1/soop_070120134.pdf

13. WHO. Vision 2020 The right to sight. Global initiative for the elimination of avoidable blindness: Action Plan 2006-2011 [homepage on the Internet]. [cited/ accessed 2017 May 19]. Available from: http://www.who.int/blindness/ Vision2020_report.pdf

14. Mashike KP, Naidoo KS. Optometric practices and practitioners in KwaZulu-Natal, South Africa. S Afr Optom. 2010;69(2):77-85. https://doi.org/10.4102/aveh.v69i2.128

15. Haffner AN. Public health value of optometry in a comprehensive health care environment. Optom Vis Sci. 1996;73:299-300. https://doi.org/10.1097/ 00006324-199605000-00001

16. Statistics South Africa. Use of health facilities and levels of selected health condition in South Africa: Findings from the General Household Survey, 2011 [www.statssa. gov]. [cited/accessed 2017 Feb 06]. Available from: www.statssa.gov.za

17. National Health Insurance for South Africa. Towards universal health coverage, 10 December 2015, Version 40 [www.health-e.org.za]. [cited/accessed 2017 Feb 20]. Available from: https://www.health-e.org.za/wp-content/uploads/2015/12/ National-Health-Insurance-for-South-Africa-White-Paper.pdf
18. Statistics South Africa. Statistical release P0301.4 Census 2011 [www.statssa.gov. za]. [cited/accessed 2017 Jan 27]. Available from: http://www.statssa.gov.za/ publications/P03014/P030142011.pdf

19. Statistics South Africa. National and provincial labour market: Youth. Q1: 2008Q1: 2014 Statistical release: P0211.4.2 [www.statssa.gov.za]. [cited 2017 Apr 23] Available from: www.statssa.gov.za/publications/P02114.2//P02114.22014.pdf

20. International Diabetes Federation. IDF diabetes atlas, sixth addition [www.idf org]. [cited/accessed 2017 Mar 23]. p. 34-35. Available from: www.idf.org/ diabetesatlas

21. Kearny PM, Whelton M, Reynolds K, Muntner K, Whelton PK, He J. Global burden of hypertension: Analysis of worldwide data. Lancet. 2005;365:217-223. https:// doi.org/10.1016/S0140-6736(05)70151-3

22. Statistics South Africa. Gender Statistics in South Africa [www.statssa.gov.za]. [cited/accessed 2016 Nov 25]. Available from: http://www.statssa.gov.za/ publications/Report-03-10-05/Report-03-10-052011.pdf

23. Statistics South Africa. Statistical Release P0301.4 Census 2011 [www.statssa.gov. za]. [cited/accessed $2017 \mathrm{Apr}$ 29]. Available from: http://www.statssa.gov.za/ publications/P03014/P030142011.pdf

24. PBODO. Binocular vision and paediatric optometry. Minimum standards for child vision care [homepage on the Internet]. [cited date not available]. Available from: http://www.hpcsa.co.za/Uploads/editor/UserFiles/downloads/optometry/ childrens vision minimum_standards.pdf

25. Ramson $P$, Govender $P$, Naidoo K. Recruitment and retention strategies for public sector optometrists in KwaZulu-Natal Province, South Africa. Afr Vision Eye Health. 2016;75(1):1-10.

26. Oduntan AO, Louw A, Moodley VR, Richter M, von Poser P. Perceptions, expectations, apprehensions and realities of graduating South African optometry students (PEAR study, 2006). S Afr Optom. 2007;66(3):94-108. https://doi. org/10.4102/aveh.v66i3.241

27. Mashige KP, Oduntan OA, Hansraj R. Opinions of South African optometry students about working in rural areas after graduation. Afr J Prim Health Care Fam Med. 2015;7(1):1-7. https://doi.org/10.4102/phcfm.v7i1.799

28. Oduntan AO, Raliavhegwa M. An evaluation of the impact of the eye care services delivered to the rural communities in the Mankweng health sub district of the Northern Province. S Afr Optom. 2001;60(3):71-76

29. Azuara-Blanco A, Burr J, Thomas R, Maclennan G, McPherson G. The accuracy of accredited glaucoma optometrists in the diagnosis and treatment recommendation for glaucoma. Br J Ophthalmol. 2007;91:1639-1643. https:// doi.org/10.1136/bjo.2007.119628 